\title{
Las potestades públicas de la AdMinistración del Estado EN LA TUTELA DE LOS INTERESES PÚBLICOS: A PROPÓSITO DE LA SENTENCIA 634/2007 Del Tribunal ConstituCiOnAL ${ }^{*}$
}

\author{
Juan Carlos Ferrada Bórquez ${ }^{* *}$
}

RESUMEN: Este trabajo analiza, a partir de la sentencia del Tribunal Constitucional 634/2006, los alcances de los intereses generales y las potestades administrativas en el Derecho Administrativo chileno. De este modo, utilizando esta sentencia como telón de fondo, se explica el rol que cumplen los intereses generales o públicos en el ordenamiento jurídico chileno, la tutela de los mismos por los órganos estatales, en particular, por los órganos de la Administración del Estado y las prerrogativas que tienen estos para aplicar las normas que establecen y resguardan esos intereses. En este contexto, se estudia cómo juegan esas categorías jurídicas en la normativa constitucional y legal sobre acceso a la documentación administrativa, teniendo como normas de referencia el nuevo artículo $8^{\circ}$ de la Constitución Política de la República y el artículo 13 de la Ley Orgánica Constitucional de Bases Generales de la Administración del Estado. Así se contrasta las construcciones teóricas en esta materia con lo resuelto por el Tribunal Constitucional en la Sentencia 634/2006, dando cuenta de las imprecisiones y equivocos en que incurre el fallo y las consecuencias que tiene ello para la comprensión sistemática del Derecho Administrativo.

Palabras Clave: Potestades - Intereses públicos - Documentación pública - Secreto.

\section{The Public Authority of the State Administration in the Tutelage of Public Interests: regarding Sentence 634/2007 of THE Constitutional Court}

ABSTRACT: This paper examines the implications of the general interests and administrative authorities in the Chilean Administrative Law, based in sentence 634/2006 of the Constitutional Court. Using this sentence as a back-

\footnotetext{
Este trabajo forma parte del proyecto de investigación FONCECYT $\mathrm{N}^{\circ} 1050395$, del que el autor es investigador principal.

** Licenciado en Ciencias Jurídicas y Sociales por la U. de Chile. Doctor en Derecho por la U. Carlos III de Madrid (España). Profesor de Derecho Administrativo en la Universidad Austral de Chile. Correo electónico: jferrada@uach.cl Fecha de recepción: 15 de abril de 2008.

Fecha de aprobación: 20 de junio de 2008.
} 
ground, it is possible to explain the role that general or public interests play in the Chilean Legal System, the tutelage of them by the state institutions, particularly, by the administrative agencies and the prerogatives that they have in order to enforce the regulations that establish and protect those interests. In this context, what is being studied is the way in which these legal categories interact in the constitutional and legal rulings concerning access to administrative documentation. The new article $8^{\circ}$ of the National Constitution and article 13 of the Constitutional Organic Statute with General Foundations of the State Administration, are kept as a reference. Then the theoretical convictions are compared in this matter with what has been determined by the Constitutional Court in Sentence 634/2006, accounting for the imprecisions and mistakes incurred in the ruling and the consequences it has for the systematic comprehension of Administrative Law.

KeY wORDs: Authority - Public interests - Public documentation Secret.

Sumario: I. Antecedentes del caso. II. Los intereses públicos en el sistema jurídico. 1. Los intereses públicos o generales. 2. Los intereses generales tutelados en el acceso a la documentación pública. III. La tutela de los intereses públicos en la organización estatal. 1. Los órganos de la Administración del Estado en la tutela de los intereses públicos. 2. Las potestades o prerrogativas de la Administración Pública en la tutela de los intereses públicos. IV. La tutela del interés público en la publicidad y en la declaración de reserva o secreto de documentos. 1. La regulación constitucional y legal de la publicidad de los documentos y antecedentes públicos y las causas de reserva o secreto. 2. Las potestades de la Administración del Estado en la tutela de estos intereses públicos. 3. La potestad del jefe superior de servicio en la declaración de reserva o secreto de documentos. 4. La "calificación" del Director Nacional de Aduanas para establecer el secreto o reserva: ¿un problema de constitucionalidad o legalidad? Conclusiones.

\section{INTRODUCCIÓN}

Durante el año 2007 se han dictado más de un centenar de sentencias por el Tribunal Constitucional (en adelante STC), número expresivo y relevante que refleja las nuevas atribuciones de este alto tribunal. Particularmente importante en este aumento explosivo de su actividad es su nuevo rol de órgano de control represivo de la constitucionalidad de las leyes, a través del denominado recurso de inaplicabilidad por inconstitucionalidad (Art. $93 \mathrm{~N}^{\circ} 6$ de la Constitución Política de la República, en adelante, CPR), por el cual juzga, a instancia de parte o del tribunal, la constitucionalidad de la aplicación de una norma legal vigente que se pretende aplicar en la resolución de un asunto judicial. 
En este contexto, en el ámbito del Derecho Administrativo, el Tribunal ha sido especialmente prolífico, pronunciándose sobre los alcances de la autonomía municipal (STC 696/2006), el contenido del derecho fundamental de acceso a los cargos y empleos públicos (STC 805/2007), la configuración de las potestades administrativas en general (STC 634/2006), del ejercicio de las potestades disciplinarias en contra de los funcionarios públicos (STC 783/2007, aunque referido a los funcionarios judiciales, perfectamente aplicable a los demás funcionarios públicos), de las funciones "jurisdiccionales" de los órganos administrativos (STC 520/2006 y más de una treintena del mismo tenor, incluyendo la STC 681/2007 que establece la inconstitucionalidad del Art. 116 del Código Tributario), entre otras materias relevantes. Estas, como se podrá adivinar, han tenido un fuerte impacto en la configuración de nuestro Derecho Administrativo, ya que han definido una línea de interpretación y aplicación de normas constitucionales claves con directa aplicación en instituciones y conceptos administrativos, lo que por lo demás tampoco es extraño considerando la estrecha vinculación que existe entre aquellas y estos ${ }^{1}$.

Así, una de estas sentencias relevantes de este año recién pasado, es la pronunciada por el Tribunal (STC 634/2006, de 9 de agosto 2007) a propósito de la constitucionalidad de una parte del inciso $11^{\circ}$ del Art.13 de la Ley Orgánica Constitucionalidad de Bases Generales de la Administración del Estado (en adelante, LOCBGAE), que establece el procedimiento de acceso a la documentación administrativa ${ }^{2}$. Esta sentencia, además de analizar con minuciosidad la regulación legislativa de este novedoso derecho de los ciudadanos para controlar directamente la actividad administrativa, cuestión desde ya relevante, se pronuncia además -en forma casi implícita- sobre el fundamento y contenido de las potestades administrativas en nuestro sistema constitucional, especialmente de las potestades declarativas de derechos y del ejercicio de la autotutela declarativa por los órganos de la Administración del Estado.

En este sentido, este artículo se va a centrar en la concepción implícita que tiene nuestro Tribunal Constitucional sobre las potestades administrativas en la STC 634/2006, en particular sobre la potestad declarativa, su configuración constitucional, sus alcances y límites, y como ello impac-

A ellas, por supuesto, debe ańadirse la extensa jurisprudencia dictada hasta 2006, en que el alto tribunal ha tenido la oportunidad de pronunciarse sobre el principio de legalidad, la reserva legal, el ámbito de la potestad reglamentaria, la potestad organizativa de los órganos de la Administración del Estado, las autonomías constitucionales, las atribuciones esenciales de los órganos administrativos, entre otras materias de importancia capital para el Derecho Administrativo. Sin duda un estudio global de todo ello es una tarea pendiente en la doctrina chilena, a lo que puede contribuir este trabajo.

2 Estando en prensa este artículo, se aprobó el proyecto de ley que regula el acceso a la documentación administrativa, desarrollando el nuevo artículo $8^{\circ}$ de la Constitución Política de la República. 
ta en el caso concreto de la regulación legal del acceso a la documentación administrativa. Para ello en este trabajo analizaré consecutivamente el contenido de los intereses públicos en el ordenamiento jurídico chileno, el papel que ostentan los órganos de la Administración del Estado en la protección de esos mismos intereses y el rol específico de estos órganos en la tutela de los intereses públicos establecidos en las normas de acceso a la documentación administrativa.

Así quedan descartados desde ya como objetivos de este trabajo, un análisis específico del principio de probidad administrativa, del derecho de acceso a la documentación estatal o de las causas de secreto o reserva, temáticas relevantes sin duda para el Derecho Administrativo y que son abordadas en esta sentencia del Tribunal Constitucional, pero que no constituyen la preocupación central de este estudio. Así tampoco se analizarán los interesantes problemas derivados del impacto de una norma constitucional posterior sobre una legislación preconstitucional, operando más una cuestión de derogación tácita más que una estricta inaplicabilidad por inconstitucionalidad, cuestión sin duda discutible, pero que curiosamente el Tribunal no se hace cargo en la sentencia. Por último, este trabajo no se referirá a la relevancia que debe tener una norma legal en la resolución del asunto para ser fundamento suficiente del recurso o cuestión de inaplicabilidad por inconstitucional, cuestión interesantísima que alude el fallo y que ameritaría un estudio específico, lo que en todo caso excede los limitados marcos de este trabajo.

\section{ANTECEDENTES DEL CASO}

Por Oficio $N^{\circ} 82$ y 114 de 2006 y N$^{\circ} 14$ de 2007, la Corte de Apelaciones de Valparaíso planteó al Tribunal Constitucional una cuestión de constitucionalidad a propósito de la aplicación del Art. 13 de la Ley Orgánica Constitucional de Bases Generales de la Administración del Estado, en el marco de un procedimiento judicial de acceso a la documentación administrativa. En concreto, en la causa judicial se impugna una resolución administrativa del Director Nacional de Aduana que deniega la petición de un particular para acceder a la documentación administrativa, fundada en la protección de los derechos e intereses de terceros.

La cuestión principal que somete la I. Corte al Tribunal es determinar la constitucionalidad del inciso $11^{\circ}$ del Art.13 LOCBGAE, en cuanto establece como causa de excepción a la publicidad de los documentos y antecedentes administrativos y, por tanto, que habilita el secreto o reserva de documentos, la afectación sensible de derechos o intereses de terceras personas, según calificación fundada efectuada por el jefe superior del órgano requerido. Así la materia a resolver, es determinar si dicho precepto 
legal, en cuanto establece como causal de excepción a la publicidad de la documentación y antecedentes en poder de la Administración del Estado la "afectación sensible de los derechos o intereses de terceras personas", según calificación fundada efectuada por el jefe superior del órgano requerido", infringe lo dispuesto en el nuevo Art. $8^{\circ} \mathrm{CPR}$, en cuanto contiene expresiones adicionales a las establecidas en aquel, ya que solo contempla como causales de excepción el debido cumplimiento de las funciones públicas, los derechos de las personas, la seguridad de la Nación o el interés nacional.

En este sentido, y más allá de las objeciones que podrían plantearse a la absoluta asimilación que ha hecho el Tribunal Constitucional de la inaplicabilidad por inconstitucionalidad y la inconstitucional ${ }^{3}$-además de sus efectos generales y particulares que establecen las normas respectivas (Art. $93 \mathrm{~N}^{\circ} 6$ y 7 CPR)-, este se le solicita un pronunciamiento, a petición de la I. Corte, sobre dos puntos concretos: a) Si la causa de excepción a la publicidad de los documentos y antecedentes administrativos establecida en el Art.13 LOCBGAE, inciso 11, referida a los "derechos e intereses de terceras personas" se encuentra comprendida en la expresión "derechos de las personas" que reconoce la Constitución, como excepción al mismo principio de publicidad (Art. $8^{\circ}$ ); b) Si la facultad atribuida al jefe superior de servicio de "calificar fundadamente" esa afectación es compatible con el mismo Art. $8^{\circ} \mathrm{CPR}$ ya referido o, por el contrario, constituye una potestad exorbitante de la Administración incompatible con el diseño constitucional, especialmente atendida la reserva legal calificada que existe en la Constitución para establecer la reserva o secreto en ciertos casos.

En otras palabras, en este último punto, se trata de determinar si la reserva legal cualificada establecida en la Constitución, inhibe a los órganos de la Administración del Estado de la calificación fundada de las circunstancias de hecho concurrentes en cada caso -proceso de subsunción- o esta subsiste, a partir de lo establecido en la Constitución y su desarrollo infraconstitucional en la ley de quórum calificado establecida. La respuesta dependerá, como se verá, del rol que se le asigna al legislador y a la Administración del Estado -o entre la ley y el acto administrativo, en términos más estrictos- en la definición y protección directa de los intereses públicos.

Sobre la distinción entre ambas instituciones, es consulta obligada el trabajo de Atria, Fernando (2001). "Inaplicabilidad y coherencia: contra la ideología del legalismo". Revista de Derecho, Universidad Austral de Chile, Vol. XII: "Justicia Constitucional", pp. 119-156. 


\section{LOS INTERESES PÚBLICOS EN EL SISTEMA JURÍDICO}

\section{Los intereses públicos o generales}

Es sabido que el Estado es una organización instrumental creada para la protección de los intereses generales de la comunidad y de cada uno de los individuos que la componen, especialmente de aquellos que esa misma comunidad estima como relevantes y le otorga, por tanto, un reconocimiento y protección jurídica. En este sentido, en el caso nuestro, el Estado chileno tiene como interés general más amplio la promoción del bien común (Art. $1^{\circ} \mathrm{CPR}$ ), fórmula abstracta que parece condensar cada uno de los intereses públicos específicos aspirados por esta comunidad política y jurídica. Así, la libertad personal, la igualdad de oportunidades o la protección del medio ambiente son intereses públicos que forman parte del "bien común" general, que el Estado deberá tutelar y desarrollar, como cumplimiento del mandato general de servicio a la persona humana.

Lo anterior lleva a que el propio ordenamiento jurídico defina pormenorizadamente esos intereses públicos específicos, pasando a ser bienes jurídicos protegidos, y asigne su tutela a algunas organizaciones o entidades públicas. Ello ha quedado determinado, por un lado, por el propio constituyente en la definición de los valores, principios y bienes jurídicos de máxima significación institucional y que, por lo mismo, han tenido un especial reconocimiento y protección en la Carta Fundamental; pero por otro, también en la legislación derivada y en los reglamentos administrativos, ya que dichas normas no constituyen mera ejecución automática de las previsiones constitucionales, sino opciones políticas de tutela y desarrollo de ciertos bienes jurídicos específicos que configuran el interés general y que la mayoría de los ciudadanos ha considerado, en el marco de la Constitución, darle una especial protección ${ }^{4}$.

Ahora bien, como es obvio, en una sociedad plural y diversa como las nuestras, los intereses generales son variados, por lo que es necesario a menudo armonizarlos y ponderarlos, atendida la situación concreta en que deben aplicarse ${ }^{5}$. Así es frecuente que frente a un interés público de desarrollo económico y creación de empleo, exista un interés de protección ambiental, debiendo el legislador establecer los criterios de ponderación de unos y otro, en razón de las prioridades definidas por los ciudadanos en un momento determinado. Ello es consecuencia inmediata y directa del principio de pluralismo político que rige en una sociedad democrática, donde las distintas opciones políticas que privilegian ciertos intereses públicos

Parejo Alfonso, Luciano et al. (1998) Manual de Derecho Administrativo. $3^{a}$ edición. Barcelona: Ariel, vol. I, pp. 606-607.

PAREJO (1998) 608. 
sobre otros constituye una manifestación normal de la democracia, articulándose ello a través del reconocimiento de una "libertad de configuración normativa" del legislador ${ }^{6}$, lo que puede hacerse también extensivo -aunque en forma mucho más acotada, como es obvio- a la Administración del Estado en el ejercicio de su poder reglamentario derivado o autónomo.

Así, estos intereses generales o públicos ya acotados o definidos específicamente dentro del ordenamiento constituyen el marco de referencia indispensable de la actividad de los poderes públicos, ya que estos, jurídicamente hablando, no tiene intereses propios ajenos a los definidos por los ciudadanos, sino justamente los intereses generales definidos por el ordenamiento jurídico ${ }^{7}$. Aún más, esos intereses públicos específicos son el fundamento de todo el poder público y su conexión con estos es lo que les permite precisamente imponerse a los intereses de los particulares, en el marco del ordenamiento jurídico. De ahí que el ejercicio de ese poder en contradicción a esos intereses constituirá una potestad ejercida con desviación de fin -o "desviación de poder" en la terminología administrativa francesa-, lo que permite en el ámbito del Derecho Administrativo la nulidad de la actuación administrativa.

\section{LOS INTERESES GENERALES TUTELADOS EN EL ACCESO A LA DOCU- MENTACIÓN PÚBLICA}

En este marco, es preciso definir, en primer lugar, el o los intereses públicos que concurren en el caso del acceso a la documentación administrativa -como ejemplo base de este trabajo y objeto del pronunciamiento del Tribunal Constitucional en la STC 634/2006- y como esos intereses se insertan en el ordenamiento jurídico chileno. Así, es evidente que la Constitución ha definido como interés general o público específico la probidad en el ejercicio de las funciones públicas (Art. $8^{\circ}$ CPR), ampliando con ello de paso la protección legal que establecía el Art.13 LOCBGAE referida a las actuaciones de los órganos de la Administración del Estado a las desarrolladas por todos los órganos estatales ${ }^{8}$.

6 García de Enterría, Eduardo y Fernández, Tomás-Ramón (2000). Curso de Derecho Administrativo. $10^{\text {a }}$ edición. Madrid: Civitas, tomo I, pp. 123-125.

7 Sánchez Morón, Miguel (2007) Derecho Administrativo. Madrid: Tecnos, p. 72.

8 Recuérdese que la Ley No 19.653 de 1999 añadió normas específicas sobre probidad administrativa, incorporando un título especial en la Ley Orgánica Constitucional de Bases Generales de la Administración del Estado en esta materia, además de regular con precisión el acceso a la documentación y actos administrativos, como mecanismo que fortalecía esta probidad. Sin embargo, dicha regulación, como se sabe, estaba circunscrita a los órganos de la Administración del Estado, ya que ese es el ámbito de aplicación de la referida ley. Ello provocó que algunos órganos estatales quedarán al margen de esta ley, lo que impidió a los particulares el acceso a alguna documentación pública. Ver, a modo ejemplar, en este senti- 
Además, dicho interés público ha sido elevado por el constituyente a la máxima categoría en nuestro sistema jurídico, desde el momento en que se le consagra directamente en la Constitución Política y más aún como un principio inserto en las bases de la institucionalidad de la República (Capítulo I CPR).

Ahora bien, para tutelar este interés general, el mismo constituyente ha establecido el principio de publicidad de los actos y resoluciones de los órganos del Estado, así como sus fundamentos y procedimientos (Art. $8^{\circ}$ CPR), generando así un instrumento de control social directo de los ciudadanos de la actividad estatal ${ }^{9}$, sin perjuicio de otros mecanismos que establece el ordenamiento para cautelar la probidad administrativa. De este modo, los ciudadanos son provistos por el orden jurídico de un derecho directo de acceso general a los documentos y antecedentes, no pudiendo el Estado impedir su acceso, salvo en los casos expresamente exceptuados por la misma norma constitucional.

En este sentido se puede sostener que el constituyente chileno, al establecer un principio general de publicidad de la actuación y antecedentes de los poderes públicos, como mecanismo privilegiado de resguardo de la probidad en el ejercicio de las funciones públicas, está otorgando a este interés público la máxima relevancia jurídica y una tutela privilegiada del mismo por los ciudadanos directamente. Sin embargo, adicionalmente, el legislador ha dispuesto un mecanismo subsidiario de esta tutela por las autoridades superiores de los órganos administrativos en vía administrativa y por los tribunales de justicia en vía judicial, en el caso de que se impida o entorpezca a los ciudadanos el ejercicio de este derecho. De este modo, el interés público y su principio que le sirve de corolario, gozan de una amplia protección jurídica, correspondiendo a los ciudadanos ejercer los derechos establecidos en el ordenamiento para hacerlos efectivos.

No obstante, como ya se señaló, el mismo constituyente reconoce la posibilidad de colisión de este principio instrumental de publicidad y acceso a la documentación pública con otros intereses públicos establecidos en el mismo ordenamiento, por lo que sin afectar el interés superior de la probidad, se establecen algunos límites a la publicidad de los documentos y antecedentes de los órganos estatales, fundados en la protección de intereses relevantes en el orden jurídico. Así se establece por el constituyente chileno, como límites al principio de publicidad general, la afectación del debido cumplimiento de las funciones públicas, los derechos de las personas, la seguridad de la Nación y el interés nacional,

do, sentencia de la Corte de Apelaciones de Santiago, "Claude Reyes con Banco Central de Chile", rol 6016/2003, en Gaceta Juridica, № 279, septiembre 2003, pp. 123-126. 
límites que actúan como una excepción calificada del principio, por lo que deben interpretarse restrictivamente a fin de no hacer inútil o inoperante este.

Lo anterior no es extraño en el ordenamiento jurídico, ya que el reconocimiento del principio no impide reconocer casos en que este cede frente a otros intereses públicos relevantes. Así, en la misma materia, en el derecho comparado, junto con establecer este principio de publicidad y acceso a los documentos públicos con carácter general se establecen causas de excepción al mismo, o de secreto o reserva, fundados en la necesidad de dar protección a diversos intereses públicos o privados de alta significación en el orden jurídico. Así, la defensa nacional, la política extranjera o internacional, las deliberaciones del Gobierno y otras altas autoridades responsables de sectores estratégicos, la política monetaria y de divisas, el crédito público, la prevención y represión de la criminalidad y las necesidades de la investigación, entre otras, son intereses públicos que justifican a menudo en el derecho comparado la excepción a la publicidad de los actos y antecedentes estatales ${ }^{10}$. Asimismo, el secreto de la vida privada, la intimidad de las personas, los expedientes personales y médicos, los procedimientos sancionatorios y disciplinarios y el secreto industrial y comercial son los intereses privados más citados como límites a este principio general de publicidad de los actos y documentos en poder de órganos estatales, constituyéndose en un bloque infranqueable para los particulares y la propia Administración estatal, no obstante los legítimos intereses de los interesados por acceder a dicha documentación.

De este modo, el sistema jurídico reconoce y da cabida a distintos intereses públicos, los que deberá armonizar y ponderar en cada caso, haciendo prevalecer unos sobre otros en conformidad a los principios y reglas que establece la misma Constitución o el legislador derivado como desarrollo del precepto constitucional. En este caso, el interés público de la probidad en el ejercicio de las funciones públicas y su principio instrumental de publicidad generará el derecho de acceso general a los documentos y antecedentes de los órganos estatales, el que solo se encontrará limitado por la concurrencia de alguna de las circunstancias o situaciones taxativamente establecidas en la norma constitucional, los que se fundan en otros intereses públicos reconocidos en la misma Constitución y que requieren, por tanto, también de protección jurídica. 


\section{LA TUTELA DE LOS INTERESES PÚBLICOS EN LA ORGANizACión ESTATAL}

\section{Los órganos de la Administración del Estado en la tutela de los intereses públicos}

Como ya se señaló, los intereses públicos constituyen la fuente de legitimación directa de todas las potestades públicas. Esto quiere decir, que solo en la medida que estemos ante la existencia de uno de ellos, tendrá sentido la actividad estatal y su imposición por sobre los intereses privados de las personas.

En este contexto, y para tutelar precisamente esos intereses públicos, el constituyente y el legislador han establecido un conjunto de órganos estatales, los que deberán interpretar y aplicar las normas jurídicas constitucionales e infraconstitucionales que consagran ese interés, actualizándolo y poniéndolo en aplicación concreta en cada caso. A esta tarea estará llamado el legislador en primer lugar, complementando la regulación constitucional si fuera el caso -que es la exigencia que prevé precisamente el Art. $8^{\circ}$ CPR-, los tribunales de justicia, interpretando y aplicando la norma en las controversias jurídicas que se sometan a su decisión, y el Gobierno y la Administración del Estado en la reglamentación normativa, en la definición de políticas públicas dispuestas para la satisfacción de ese interés público y, en fin, en la aplicación administrativa de esas normas en los casos concretos en que se ejerciten los derechos para la tutela de los intereses públicos.

De este modo, son los tribunales y los órganos de la Administración del Estado a los que les corresponden aplicar singularizadamente las normas jurídicas, haciendo el proceso de aplicación de estas a un caso concreto. Así, en el ámbito específico de la actuación pública corresponderá, por regla general, a la Administración estatal, organización profesional, burocrática y jerarquizada (Art. $38 \mathrm{CPR}$ ) puesta bajo la dirección del Gobierno (Art. 24 CPR y $1^{\circ}$ LOCBGAE), dar aplicación inmediata a las normas jurídicas que establecen la tutela de los diversos intereses públicos. Ello porque el legislador y los tribunales por sus atribuciones solo actuarán en forma episódica y ocasional en la tutela de esos intereses, correspondiéndole a los órganos de la Administración la aplicación diaria de las cláusulas normativas, especialmente las que requieren de una actividad directa prestacional o de acción.

En este sentido, en el caso chileno, corresponderá a los órganos que integran los distintos departamentos ministeriales en que se estructura la Administración estatal, la labor prioritaria en la definición, control y supervisión de las políticas, programas y normas que configuran esos intereses públicos (Art. 22 LOCBGAE). Sin embargo, serán los denominados servicios públicos, órganos encargados en general de la satisfacción de las necesidades colectivas de manera regular y continua (Art. 28 LOCBGAE), 
los que actuarán periódicamente a instancia de los ciudadanos o de oficio, dando contenido a los intereses públicos definidos por el ordenamiento jurídico. A ellos deben añadirse, claro está, a las municipalidades (Art. 118 CPR) y a otras organizaciones públicas que escapan a la tipología anterior, los que también tienen asignado la tutela de específicos intereses públicos que justifican su creación y legitiman su actuación ${ }^{11}$.

En dicha labor, los órganos de la Administración estatal deberán interpretar y aplicar las normas jurídicas que consagran ese interés, cuestión que evidentemente excede de una mera aplicación mecánica de las mismas, en la concepción ideal revolucionaria francesa de fines del XVIII. En efecto, como lo sostiene la doctrina comparada más relevante, ya no es posible seguir afirmando como a fines del siglo XVIII que la Administración del Estado sea un simple órgano ejecutor de la ley en la tutela de los intereses públicos ${ }^{12}$, sino que debe reconocerse a la Administración un cierto ámbito de discrecionalidad en la tutela de esos intereses públicos, lo que es coherente con la legitimación democrática directa o indirecta de su órgano directivo (el Gobierno) y con la flexibilidad de la cláusulas normativas establecidas para la satisfacción de los intereses generales ${ }^{13}$. Ello incluso ha llevado a algún sector doctrinal a reivindicar un espacio propio para la actividad de la Administración -teoría de la "reserva de Administración"14-, el cual no podría ser invadido ni aun por el legislador, ya que él estaría definido por el sistema constitucional.

Lo anterior no significa, evidentemente, desapoderar al legislador o al juez de su labor de tutela de los intereses públicos, pero la actuación de ellos será más excepcional y un estadio distinto a la aplicación inmediata de la norma, ya sea en su generación inicial, ya en la revisión posterior de la aplicación que ha hecho de la misma la Administración del Estado.

\section{Las potestades o prerrogativas de la Administración Pública en la tutela de los intereses públicos}

En el contexto antes expuesto, la tutela de los intereses públicos por la Administración del Estado deberá estar acompañada de potestades

11 En este sentido, puede tomarse como ejemplo el Banco Central de Chile, órgano que escapa a la tipología tradicional de ministerio/servicio público, pero que evidentemente forma parte de la institucionalidad estatal y tiene como objetivos específicos la estabilidad monetaria y el funcionamiento regular del sistema de pagos (Art. 3o Ley Orgánica Constitucional del Banco Central de Chile). Ver, en este sentido, Ferrada, Juan Carlos (2003) "La autonomía del Banco Central de Chile: reflexiones acerca de este modelo institucional de gestión de la política monetaria". Revista Chilena de Derecho, vol. 30 No 1, pp. 152-155.

14 Maurer y Schnapp, citados por Muńoz Machado (2006) 392-393. 
administrativas específicas que determinan la competencia o ámbito de acción específico que posee la Administración para la tutela de la materia de que se trata. Estas potestades, constituyen poderes jurídicos especiales o prerrogativas que atribuye el ordenamiento -y especialmente, el legislador- a los órganos administrativos para la tutela de los intereses públicos puestos bajo su resguardo y que permiten, precisamente, en un plano de desigualdad, dar protección a dichos intereses por sobre los intereses privados involucrados ${ }^{15}$. Así, se le reconocen a la Administración prerrogativas de acción y de protección, las que tienden a reconocer un estatuto jurídico peculiar a su actividad administrativa, imponiéndose, prima facie, a los derechos de los particulares ${ }^{16}$.

Dentro de estas la prerrogativa de acción más reconocida es el poder de actuar unilateralmente e imponer sus decisiones a los particulares ${ }^{17}-0$ poder de autotutela como lo identifican García de Enterría y Fernández ${ }^{18}$, prerrogativa que supone el reconocimiento de un poder innovativo particular a la acción administrativa, ya que en el ejercicio de la potestad administrativa hace una interpretación y una aplicación de una norma general, creando un producto nuevo en el ordenamiento jurídico ${ }^{19}$. Es decir, la Administración del Estado interpreta y aplica el derecho, interpretación y aplicación que es obligatoria para los particulares afectados por la decisión administrativa, la que se impone a sus intereses atendida la posición institucional y el interés público que protege. Ello no impide, como es obvio en un Estado de Derecho, la impugnación posterior del acto administrativo ante los tribunales de justicia, e incluso su nulidad posterior, en el caso de que este se haya dictado con infracción al ordenamiento jurídico.

Estas potestades administrativas así concebidas constituyen un elemento propio de los órganos de la Administración del Estado que identifican su institucionalización en el ordenamiento jurídico. Aún más, la existencia misma del Estado y el reconocimiento de ciertos intereses como públicos, fundamentan la existencia misma de estas potestades, como ya se vio, siendo esto un elemento central indiscutible de los ordenamientos herederos del régimen administrativo francés ${ }^{20}$. Sin embargo, esta concepción también tiene cabida parcialmente en el derecho anglosajón -derecho muy reacio en general al reconocimiento de desigualdades en el sistema jurídico-, aunque en este caso estas prerrogativas no están radicadas en los órganos administrativos en general, sino en las denominadas "agencias

Rivero, Jean y Waline, Jean (2006) Droit administratif. 21a edition. París: Dalloz, p. 3.

Chapus, René (2001) Droit administratif general. $15^{\text {a }}$ edition. París: Montchrestien, tome 1, pp. 469 y ss.

Chapus (2001) 470.

García de Enterría y Fernández (2000) 487 y ss.

Braibant, Guy (1992) Le droit administratif français. París: Presses de la Fondation nationale du sciences politiques \& Dalloz, pp. 171-172.

Benort, Francis-Paul (1968) Le droit administratiffrançais. París: Dalloz, pp. 56 y ss. 
administrativas", las que concentran en su seno potestades materialmente legislativas, ejecutivas y judiciales, pero con un contenido diverso del asignado a estos términos en el derecho continental ${ }^{21}$.

Ahora bien, en el derecho chileno estas potestades también tienen reconocimiento jurídico, ya en un plano más general, como aplicación de las cláusulas generales de aplicación y ejecución de las leyes dispuestas para el ejercicio de sus atribuciones por parte del Presidente de la República (Arts. 24, 27 y 32 CPR), ya como potestades específicas de autotutela declarativa y ejecutiva de los actos administrativos por parte de los órganos de la Administración del Estado (Arts. $3^{\circ}$ y 51 de la Ley $N^{\circ} 19.880$ de Bases de los Procedimientos Administrativos, en adelante LBPA) ${ }^{22}$.

Estas potestades permiten precisamente a los órganos de la Administración estatal dictar actos administrativos unilaterales para tutelar alguno de los intereses públicos puestos bajo su acción, constituyendo una aplicación pormenorizada de la norma legal general dispuesta para la tutela del interés público específico. Estos actos se imponen a los particulares, en virtud de la presunción de validez de que están revestidos (Art. $3^{\circ}$ LBPA), posibilitando incluso su ejecución administrativa inmediata (Art. 51 LBPA), afirmación que debe entenderse, como ya se dijo, sin perjuicio de la posibilidad de impugnación administrativa o judicial, según el caso (Art. 54 LBPA).

En este contexto, en nuestro derecho, así como en la mayoría de los ordenamientos jurídicos comparados, los órganos de la Administración del Estado tienen potestades para dictar actos administrativos, los que constituyen una aplicación concreta de normas jurídicas generales dispuestas en el ordenamiento jurídico para la tutela de intereses públicos específicos. Dichos actos son interpretación y aplicación de esas mismas normas, los que se imponen a los particulares en virtud de las prerrogativas de autotutela, los que, sin embargo, pueden impugnarla si estiman que ello se opone al ordenamiento jurídico.

Así la interpretación y aplicación de normas jurídicas por la Administración del Estado, a través de la dictación de actos administrativos que pretenden tutelar un interés público específico, constituye una manifestación regular de las prerrogativas de la Administración, lo que no supone alteración alguna del sistema constitucional vigente. Al contrario, su negación constituiría una alteración significativa en este esquema, el que podría establecerse en un caso concreto, previa habilitación normativa -aun constitucional a veces- que asignara dicha competencia a otro órgano estatal.

Schwartz, Bernard (1991) Administrative Law. $3^{a}$ edition, Bolton Toronto, London: Editorial Advisory Board Little, Brown and Company, pp. 1-2 y 9 y ss.

22 Ferrada, Juan Carlos (2007) "Las potestades y privilegios de la Administración Pública en el régimen administrativo chileno". Revista de Derecho, Universidad Austral de Chile, vol. XX, No 2, pp. 78-79. 


\section{LA TUTEla DEL INTERÉS PÚBLICO EN LA PUBLICIDAD Y EN LA DE- CLARACIÓN DE RESERVA O SECRETO DE DOCUMENTOS}

\section{La regulación constitucional y legal de la publicidad de los docu- mentos y antecedentes públicos y las causas de reserva o secreto}

Establecido el marco jurídico general en el que actúan los intereses públicos y las potestades administrativas en el ordenamiento chileno, resta ahora determinar cómo entonces operan estos elementos en el ámbito específico de la reserva o secreto de documentos públicos, ámbito que aborda la STC 634/2006.

El punto de partida no puede ser otro que la norma constitucional, la que establece (Art. $8^{\circ}$ ), como ya se señaló, que el principio general es la publicidad de los documentos y antecedentes públicos, como expresión del interés general de la probidad en el ejercicio de las funciones públicas. Sin embargo, la misma norma constitucional establece cuatro excepciones a este principio que habilitarían el secreto o reserva del documento, las que deberán regularse específicamente mediante una ley de quórum calificado. Estas son, como ya se adelantó, la afectación del debido cumplimiento de las funciones públicas, los derechos de las personas, la seguridad de la $\mathrm{Na}$ ción y el interés nacional.

Por su parte, la LOCBGAE establece en su Art.13 el mismo principio de publicidad de los documentos y antecedentes que obren en poder de los órganos de la Administración del Estado, estableciendo como excepciones a ello los casos de afectación de derechos e intereses de terceros, ya sea de por oposición de esos terceros o de oficio por la Administración; que la publicidad impida o entorpezca el debido cumplimiento de las funciones del órgano administrativo; la afectación de la seguridad de la Nación o el interés nacional; o, en fin, que el secreto o reserva de la documentación haya sido establecido por norma legal o reglamentaria.

Como fácilmente se puede apreciar, existe una notable coincidencia entre la regulación constitucional y la establecida en la Ley Orgánica Constitucional, afirmándose el mismo principio de publicidad general, amparándose en la tutela del interés público de la probidad, y estableciendo solo causas de excepción a la misma que habilitarían el secreto o reserva de documentos. Incluso estás mismas causas de excepción se repiten casi textualmente, solo con dos excepciones, como lo hace notar el propio Tribunal Constitucional en su STC 634/2006: la habilitación legal al legislador o al poder reglamentario para disponer el secreto o reserva de documentos amparados en estas causas legales; y la ampliación legal de la protección a no solo los derechos de las personas como señala la Constitución, sino también a los intereses de terceros.

Respecto de lo primero, la habilitación legislativa para regular el secreto o reserva de documentos incluso al poder reglamentario de los ór- 
ganos de la Administración del Estado, es evidente -aunque no lo dice el Tribunal- que ello no guarda relación con el texto constitucional actual, más aún cuando el constituyente encomendó a un tipo cualificado de ley (una ley de quórum calificado) la regulación de estas excepciones al principio de publicidad ${ }^{23}$. De este modo, el constituyente pareciera demostrar la relevancia del interés público comprometido con esta norma, estableciendo una reserva legal especial para la regulación de esta materia -exigencia que no la establece el constituyente ni siquiera para los derechos fundamentales-, impidiendo con ello que por vía reglamentaria se limite o entorpezca el derecho, como de hecho ocurrió bajo la vigencia exclusiva de la Ley Orgánica Constitucional de Bases Generales de la Administración del Estado $^{24}$.

En relación a lo segundo, la protección ampliada de la Ley de los derechos e intereses de las personas involucradas y de terceros, yendo más allá, aparentemente, de lo dispuesto en la Constitución ("derechos de las personas"), el Tribunal Constitucional ha razonado en el sentido de entender incorporado el concepto de "interés" dentro del vocablo más estricto de "derechos". Así, citando alguna doctrina comparada y nacional -cuya pertinencia y relevancia es bien discutible en este caso- considera legítimo la ampliación de la excepción de secreto o reserva no solo a la protección de derechos subjetivos, sino también a intereses, en la medida que estos últimos constituyen posiciones jurídicas que también reciben protección en el ordenamiento jurídico nacional (considerandos $18^{\circ}$ a $22^{\circ}$ STC 634/2006). De este modo, la regulación legal en este punto es, a juicio del Tribunal, plenamente coherente con el texto constitucional, por lo que no puede ser objetada su constitucionalidad (considerando $23^{\circ}$ STC 634/2006).

En este sentido, para el Tribunal Constitucional el problema se plantea solo -y ese es el objeto de análisis central- en las potestades de la Administración en la aplicación de las causales de excepción a la publicidad y el acceso a los actos y documentos administrativos y, en particular, con la protección de los intereses de terceros, considerando la reserva legal calificada que hace el precepto constitucional para regular esta materia.

\footnotetext{
23. En este mismo sentido se pronuncia por lo demás el Tribunal al dar cuenta de la restricción cualificada que realiza el constituyente (considerandos $10^{\circ}$ y $13^{\circ}$ STC 634/2006).

24 Recuérdese que bajo la exclusiva vigencia de la LOCBGAE, se dictó el Decreto Supremo No 26/2001, del Ministerio Secretaría General de la Presidencia, que no solo desarrolló la habilitación legal dispuesta en el inciso final del Art. 13 LOCBGAE, sino que amplió materialmente las causales de excepción a la publicidad y acceso a la documentación. Además, habilitó a los jefes de los servicios públicos para dictar resoluciones administrativas que pormenorizaran los documentos acogidos a esta excepción, lo que en conjunto con la regulación expansiva de las causales antes apuntada, abrió los casos de excepción ilimitadamente, haciendo inoperante el principio general. En este sentido, puede verse Allesch, Johann y OBANDo, Iván (2004). "Una visión crítica sobre la normativa de acceso a los actos e información administrativa". Ius et Praxis, vol. 10, № 2, pp.11-58.
} 


\section{Las potestades de la Administración del Estado en la tutela de estos intereses públicos}

Pues bien, en este contexto, ¿qué rol le cabe a los órganos de la Administración del Estado? ¿Puede el jefe superior de un servicio público establecer la reserva o secreto de documentos, aplicando las normas constitucionales o legales de referencia? ¿Qué alcances tiene esa calificación jurídica?

Como se sabe la Constitución nada dice al respecto, solo remite a una ley de quórum calificado el establecimiento de la reserva o secreto, cuando concurran las causales allí establecidas. Por su parte, la LOCBGAE establece, como ya señaló, un rol activo del jefe superior, ya sea recibiendo la petición del particular (Art.13 inciso $5^{\circ}$ ), incoando y tramitando un procedimiento administrativo de acceso a la documentación administrativo (Art.13 incisos $6^{\circ}$ y $7^{\circ}$ ), resolviendo favorablemente la petición o rechazándole por oposición de terceros (Art.13 incisos $8^{\circ}$ y $9^{\circ}$ ), denegando el acceso a la documentación por aplicación de las causas de excepción establecidas en la ley (Art.13 incisos $10^{\circ}$ y $11^{\circ}$ ) y, en fin, realizando sus descargos en el procedimiento judicial de impugnación del acto administrativo que estableció el secreto o reserva del documento o antecedente (Art.14 letra c).

Como se puede observar, a los jefes superiores de servicio público les está atribuida en nuestro derecho una serie de potestades en la materialización de este procedimiento de acceso a la documentación administrativa, asumiendo directamente la tutela de los intereses públicos comprometidos. Lo anterior no parece extraño, si se considera, por una parte, que son los propios servicios públicos los tenedores materiales de los documentos que pretende conocer y obtener el particular; y por otra, como ya se dijo anteriormente, que la aplicación de la normativa legal corresponde en forma habitual a los servicios públicos, órganos encargados por la Constitución y la Ley de tutelar en forma preferente los diversos intereses públicos, una vez configurados jurídicamente.

Por lo demás, lo mismo ocurre en el derecho comparado, donde las potestades procedimentales, de acceso y de secreto o reserva de documentos esta atribuida a los órganos administrativos especializados (Estados Unidos) o comunes (Francia, Italia o España) y, por tanto, la relación primera se produce entre el particular peticionario y la Administración esta$\mathrm{tal}^{25}$

Ahora lo anterior no significa, evidentemente, atribuir en todos estos casos a la Administración un poder omnímodo e incontrolado de reserva o secreto de documentos. Al contrario, se configura como una potestad reglada o discrecional, según el caso, pero que debe ser aplicación estricta 
de la normativa legal o reglamentaria de referencia, debiendo dictar un acto motivado - "calificación fundada" - en caso de rechazo al principio general de publicidad establecido. Aún más, ese acto denegatorio puede ser impugnado ante los tribunales de justicia, haciendo efectivo así el derecho de tutela judicial que tienen reconocido las personas en la mayoría de los ordenamientos constitucionales y que en nuestro derecho se establece en los Arts. $19 \mathrm{~N}^{\circ} 3$ y $38 \mathrm{CPR}$.

En este contexto, como se puede observar, las potestades del jefe de servicio en esta materia constituyen una aplicación concreta de la forma regular de tutela de los intereses públicos en el ordenamiento jurídico, en la que a la Administración se le encomienda prima facie interpretar y aplicar el derecho, satisfaciendo los intereses generales definidos por aquel (Art. 13 LOCBGAE). Así, esa aplicación no es más que una ejecución pormenorizada del derecho por la Administración del Estado (Arts. 24 y $27 \mathrm{CPR}$ ), la que realizará por un acto administrativo (Arts. $3^{\circ}$ inciso $3^{\circ}$ LBPA), el que goza de una presunción de validez (Arts. $3^{\circ}$ inciso $7^{\circ}$ LBPA) y está premunido de un poder de ejecutoriedad inicial (Arts. 51 LBPA), lo que no obsta a que puede ser impugnado por el particular ante los tribunales de justicia (Arts. 38 CPR y 54 LBPA). En ello no parece haber nada excepcional, simple concreción de los principios y reglas de funcionamiento regular del sistema jurídico administrativo.

\section{La potestad del jefe superior de servicio en la declaración de re- serva o secreto de documentos}

Establecido lo anterior, queda por determinar -que es lo relevante en la STC 634/2006- si entre estas potestades del jefe superior del servicio en esta materia, es constitucionalmente válido asignar legalmente a este la reserva o secreto de documentos, a través de una "calificación fundada", cuando a su juicio ello "afecte sensiblemente los derechos o intereses de terceras personas", como lo establece la LOCBGAE (Art.13 inciso $11^{\circ}$ ).

Ya ha quedado establecido que es constitucionalmente válido asignar potestades a la Administración del Estado para interpretar y aplicar el derecho, más aún cuando esa aplicación esta directamente relacionada con la tutela de los intereses públicos definidos ya por el constituyente y el legislador. Por lo anterior, en este caso, es conforme con la Constitución asignar al jefe superior de un servicio público las potestades para recibir las peticiones de acceso a la documentación, incoar el procedimiento administrativo correspondiente y resolver inicialmente la petición conforme a derecho. Ahora bien, jello incluye la potestad de "calificar fundadamente" la "afectación sensible de derechos o intereses de terceras personas", impidiendo el acceso de los particulares a esa documentación?

Es evidente que la denegación de un documento o antecedente por el jefe superior de un servicio público solo puede hacerse, constitucional y 
legalmente, solo si concurren algunas de las causas de excepción establecidas en el ordenamiento jurídico. Solo en tal caso va a concurrir un interés público jurídicamente relevante que va a impedir que opere el principio general, de rango constitucional, de publicidad de los documentos y antecedentes, habilitando a la Administración a ejercer su potestad denegatoria. Ello exige que el órgano de la Administración del Estado, frente a la petición de un particular, analice con toda precisión si concurre en la especie esa causa de excepción o no, lo que debe explicitar en la motivación (vistos) del acto administrativo respectivo.

Lo anterior es lo que precisamente señala el inciso $10^{\circ}$ del Art.13 LOCBGAE al establecer que el "jefe superior del órgano requerido deberá proporcionar la documentación que se les solicite, salvo que concurra alguna de las causales que establece el inciso siguiente, que le autorizan a negarse. En este caso, su negativa a entregar la documentación deberá formularse por escrito y fundadamente, especificando las razones que en cada caso motiven su decisión" (la cursiva es mía). Es decir, corresponde al jefe del servicio público interpretar la normativa constitucional y legal vigente, y en base a ello acceder o rechazar la petición del ciudadano de acceso a la documentación administrativa.

En este contexto parece evidente que una de esas causas de excepción que habilitan esa negativa es la afectación de "derechos e intereses de terceras personas", ya que según lo ha entendido el propio Tribunal Constitucional, como ya se vio, los "intereses" forman actualmente parte de la categoría genérica de "derechos" que establece literalmente la norma constitucional (Art. $8^{\circ} \mathrm{CPR}$ ). En otras palabras, la potestad de denegar el acceso a los documentos o antecedentes que están en poder de la Administración del Estado puede fundarse en cualquiera de las causas de excepción establecidas en la Constitución, entre las que se encuentra la "afectación de derechos o intereses de terceras personas".

En este sentido, al contrario de lo que resuelve nuestro Tribunal Constitucional, parece plenamente conforme con la Constitución la potestad asignada a los jefes superiores de servicio público para denegar "fundadamente" el acceso de los ciudadanos a un documento o antecedente que obren en su poder por afectar, a su juicio, sensiblemente los derechos o intereses de terceras personas, como lo establece el Art. 13 inciso $11^{\circ}$ LOCBGAE. Más aún, el resguardo adicional ("calificación fundada"), pero innecesario, atendido lo dispuesto en los Arts. 11 y 41 LBPA, que impone el legislador para el ejercicio regular de la potestad, constituye una garantía para los ciudadanos, que permitirá una revisión judicial más estricta de aquella.

En este contexto parece inexplicable la resolución del Tribunal Constitucional declarando inaplicable por inconstitucional el precepto legal que establece la potestad para "calificar fundadamente" la "afectación sensible de derechos e intereses de terceros". 
¿Pero cómo llega entonces a ello el Tribunal? ¿Cuál es el argumento determinante para la resolución del asunto discutido?

Aparentemente el Tribunal comete un yerro capital. Confunde las funciones de regulación y calificación para la tutela del interés público dispuestas en la Constitución y en la LOCBGAE. Es decir, a partir de la reserva legal (y de ley de quórum calificado) establecida en la Constitución para regular los casos de reserva o secreto de documentos o antecedentes, sobre la base de las causas de excepción el mismo precepto plantea (Art. $8^{\circ}$ CPR), infiere una prohibición para la Administración para calificar dichas causas. En otras palabras, como la regulación es privativa del legislador, los jefes superiores de servicio no pueden "calificar" su procedencia.

Lo anterior es absurdo y no se sostiene. Es evidente que hay una reserva legal para la regulación específica de los casos en que se pueden presentar las causas de excepción al principio general de publicidad de los documentos o antecedentes que están en poder de los órganos del Estado. Sin embargo, ello no impide que la Administración analice y califique, prima facie, en cada caso, la procedencia o no de esas causas de excepción, más aún cuando el legislador - a esa fecha- no ha dictado la legislación de desarrollo de la normativa constitucional. Dicha "calificación", que en el fondo es la interpretación y aplicación de la normativa constitucional y legal, es lo que precisamente está llamado a hacer la Administración, como ya se ha expuesto anteriormente, dictando los actos administrativos pertinentes que tutelen los intereses públicos comprometidos en este caso.

Esa es la función constitucionalmente asignada a la Administración y que el legislador orgánico constitucional se encarga de regular específicamente. Lo contrario sería exigir a futuro a la regulación legal de desarrollo del Art. $8^{\circ} \mathrm{CPR}$ una precisión y detalle que hiciera innecesaria la intervención de la actividad administrativa, lo que parece insensato, además de imposible.

Confirma lo expuesto anteriormente, los propios antecedentes de la historia fidedigna del establecimiento de la norma, y curiosamente citado por el Tribunal. En efecto, la cita textual al senador Hamilton (considerando $27^{\circ}$ ), como argumento para oponerse a la potestad de la Administración para calificar los casos de secreto o reserva, no hacen más que ratificar la interpretación dada en el párrafo anterior y rechazar la resolución del Tribunal, desde el momento en que aquel no niega la actividad administrativa de aplicación de la normativa, sino que solo se preocupa de resaltar la necesidad de que ella no puede ser arbitraria, deba ser "fundada" y deja abierta la posibilidad de impugnarla ante los tribunales de justicia ${ }^{26}$.

26 La cita textual del considerando $27^{\circ}$, en lo pertinente es la siguiente: "Confirmando que el Constituyente de 2005 no quiso dejar entregada a los propios órganos del Estado la determinación de la concurrencia de las causales constitucionales de secreto o reserva, debe recordarse que, tal y como lo expresó el Senador Juan Hamilton, durante el mismo debate 
Otra cosa distinta -y quizás a esto pretendía apuntar el Tribunal- es que la Administración del Estado dicté reglamentos específicos que regulen los casos de excepción de reserva o secreto de documentos, ámbito en el que es absolutamente incompetente, según dispone la Constitución, y contempla ilegítimamente la normativa legal preconstitucional dictada en su oportunidad (Art.13 LOCBGAE). Esto si está prohibido por la Constitución y su ejercicio por la Administración, si ocurriera, debería ser censurado por el Tribunal.

No obstante lo expuesto, podría haber otra interpretación para la resolución del Tribunal; que la inconstitucionalidad de la regulación legal del secreto o reserva esté referido a la actuación de oficio del órgano administrativo en la protección de estos intereses y no la causal invocada. En otros términos, que lo que censura el Tribunal no sea la calificación que realiza el órgano administrativo, sino que haya ejercido esta facultad sin previa oposición de los terceros interesados, como lo señala el mismo inciso unas líneas más arriba. Sin embargo, ello parece improbable ya que no existe ningún razonamiento del fallo que pueda llevar a ello y además no sería concordante con la regulación general de los procedimientos administrativos, que permite el inicio de estos a petición de los interesados o de oficio, sin que exista diferencia material en uno u otro caso (Art. 28 y ss. LBPA).

\section{La "calificación" del director Nacional de Aduanas para estable- cer el secreto o reserva: ¿un problema de constitucionalidad o legalidad?}

Despejado lo anterior, falta determinar si el ejercicio concreto de esta potestad de reserva o secreto realizada por el Director Nacional de Aduanas, jefe superior de servicio público, de acuerdo a los antecedentes que obran en la STC 634/2006 se realizó conforme a la Constitución y las normas legales aplicables.

Es claro que la potestad del Director Nacional de Aduanas se ejerció a través de un acto administrativo, quien analizado los antecedentes del caso, dispuso, aparentemente, de oficio, el secreto o reserva de documentos, atendido la afectación de derechos e intereses de terceros. En este sentido, el acto es aplicación del Art.13 LOCBGAE, según indica el propio requerimiento del abogado de la peticionaria de los documentos.

parlamentario de esa reforma, 'en general, todos los documentos son públicos, excepto que esté comprometido el derecho de las personas, la seguridad de la Nación o el debido funcionamiento del servicio, pero no queda al arbitrio del funcionario público el negar la información. Si éste la niega, debe fundar su negativa en alguna de estas causales y si el reclamante no concuerda, se prevé un procedimiento breve y expedito para que el juez resuelva'. (Ibídem);" (la negrilla está en el texto original citado). 
En este contexto, el cuestionamiento del abogado, según lo expuesto en la parte expositiva de la propia STC 634/2006, se extiende a la facultad ejercida por el Director Nacional de Aduanas (constitucionalidad de la potestad), como al ejercicio mismo de ella, en forma arbitraria, de oficio, sin consulta previa a los interesados y de modo totalmente discrecional. Resuelto entonces en el punto anterior, la constitucionalidad de la facultad, queda por determinar si su ejercicio se conformó a la Constitución.

Como se puede observar, las objeciones planteadas por el abogado requirente implican un cuestionamiento a la forma como ejerció la potestad administrativa el Director Nacional de Aduanas, transgrediendo principios y reglas del ejercicio regular de una potestad pública. Así, imputa a la actuación administrativa discrecionalidad extrema y arbitrariedad, falta de motivación de la decisión y inexistencia de audiencia de los interesados en el procedimiento administrativo seguido. Tales imputaciones son, evidentemente, objeciones de legalidad al ejercicio de la potestad administrativa, que de ser efectivas vulnerarían, en principio, el propio Art.13 LOCBBGAE, así como los Arts. $3^{\circ}$ y $8^{\circ}$ LOCBGAE y 11 y 41 LBPA. En otros términos, las cuestiones de trascendencia jurídica para la resolución del asunto se encuentran reguladas en la ley, por lo que el conflicto jurídico es un típico contencioso administrativo de mera legalidad, competencia de los tribunales ordinarios de justicia y, en este caso, del juez de letras en lo civil en primera instancia, y de la Corte de Apelaciones respectiva en vía de apelación.

Bien es cierto que dichas ilegalidades podrían eventualmente constituir en último término una vulneración a normas constitucionales generales como la interdicción de la arbitrariedad o la exigencia de un procedimiento racional y justo -en la versión chilena del ejercicio de la jurisdicción ${ }^{27}$-, pero ellas se reconducen en este caso a las cuestiones de legalidad perfectamente impugnables en el procedimiento judicial establecido por la LOCBGAE para estos casos.

En todo caso, es preciso señalar que aun cuando se considerase que la controversia jurídica es de naturaleza constitucional, nuestro Tribunal Constitucional no tiene facultades para resolver esta materia, ya que los problemas de inconstitucionalidad de una resolución administrativa dictada por un jefe de servicio no caben dentro de las atribuciones taxativas establecidas en la Carta Fundamental, sino solo los decretos y resoluciones del Presidente de la República, que hayan sido representados por la Contraloría General de la República en el trámite de toma de razón (Art. 93 $\mathrm{N}^{\circ} 9 \mathrm{CPR}$ ). Cierto es que el Tribunal ha extendido excepcionalmente ese control hacia resoluciones dictadas por un ministro de Estado, argumen-

27 Bordalí, Andrés y Ferrada, Juan Carlos (2008) "La tutela judicial del ciudadano frente a la Administración del Estado", en Estudios de Justicia Administrativa, Santiago: LexisNexis. 
tando la naturaleza de decreto supremo reglamentario que tendría esa resolución (STC 591/2006), pero ello ha sido una sentencia de excepción, tanto en relación a los argumentos utilizados - con una confusión conceptual increíble entre decretos supremos, resoluciones y reglamentos-como en la cuestión de fondo resuelta -la regulación de la entrega gratuita de la denominada "píldora del día después-.

Por lo demás, es evidente que la resolución del Director Nacional de Aduanas, negando el acceso a la documentación solicitada no es ejercicio de potestad reglamentaria alguna, por lo que aun siguiendo la doctrina del Tribunal Constitucional en la STC 591/2006, no es posible atribuir al mismo competencia para resolver esta materia, de acuerdo al Art. $93 \mathrm{~N}^{\circ} 9$ CPR.

En este contexto, es obvio que cualquier discusión acerca de la constitucionalidad de la resolución administrativa debe ser discutida en sede judicial ordinaria, ya que es dicha judicatura la competente para resolver las controversias derivadas de la emisión de un acto administrativo con infracción al ordenamiento jurídico.

\section{CONCLUSIONES}

Como se puede observar, la STC 634/2006 es un campo muy interesante para analizar y poner en juego algunos conceptos e instituciones del Derecho Administrativo. Desde luego permite analizar el concepto de interés público en el ordenamiento jurídico, las potestades administrativas dispuestas para la tutela de esos intereses y los criterios de prioridad y armonización de esas potestades. Pero también permite, desde una perspectiva más general, observar cuál es la concepción del Tribunal Constitucional de nuestro Derecho Administrativo y de las potestades que puede desarrollar la Administración del Estado al interior de este.

En este sentido, parece evidente que el Tribunal Constitucional descansa -sin saberlo- en una concepción decimonónica del Derecho Administrativo, en la que la tutela de los intereses públicos corresponde solo al legislador y a la Administración del Estado no le cabe otra cosa que aplicar mecánicamente la ley en los supuestos específicos y tasados por el ordenamiento. Así, el ejercicio de potestades públicas que limiten o restrinjan derechos de los particulares, en protección de intereses públicos, con poderes de autotutela y amparado con la presunción iuris tantum de validez, constituyen conceptos que parecen desconocer los miembros del Tribunal, pese a que el ordenamiento jurídico chileno los consagra expresamente y la doctrina más actual lo afirma categóricamente.

Lo anterior genera, como se puede ver en este caso, serios problemas de aplicación de las normas legales, llegando incluso a la inoperatividad 
de las mismas. De este modo, a partir de ciertas cláusulas constitucionales abstractas el Tribunal Constitucional construye normas -o prohibicionescompletamente contradictorias con el resto del sistema jurídico, afectando con ello las bases de las disciplinas jurídicas especializadas y la coherencia del sistema.

Cierto es que se podría sostener que, en este caso, el Tribunal Constitucional con su fallo hizo justicia material, permitiendo la preeminencia del interés público prioritario de la probidad administrativa. Sin embargo, a mi juicio, al Tribunal Constitucional debe exigírsele algo más. Debe exigírsele que actúe conforme a Derecho, aplicando la Constitución y evitando teñir sus fallos de mero ejercicio de equidad natural. Como ya lo sostuvo el juez Coke hace casi cinco siglos "...las causas que conciernen a la vida, la herencia, los bienes o la fortuna de sus súbditos no deben ser decididos por la razón natural, sino por la razón artificial y el juicio del Derecho..."28.

\section{Bibliografía CITADA}

- Allesch, Johann y Obando, Iván (2004). "Una Visión Crítica Sobre La Normativa de Acceso a los Actos e Información Administrativa". Ius et Praxis, vol. $10, \mathrm{~N}^{\circ} 2$.

- Atria, Fernando (2001) "Inaplicabilidad y coherencia: contra la ideología del legalismo". Revista de Derecho, Universidad Austral de Chile, vol. XII: "Justicia Constitucional".

- Benoit, Francis-Paul (1968) Le droit administratif français. París: Dalloz.

- Bordalí, Andrés y Ferrada, Juan Carlos (2008) "La tutela judicial del ciudadano frente a la Administración del Estado", en Estudios de Justicia Administrativa, Santiago: LexisNexis.

- Braibant, Guy (1992) Le droit administratif français. Paris: Presses de la Fondation nationale du sciences politiques \& Dalloz.

- Chapus, René (2001) Droit administratif general. $15^{a}$ edition. París: Montchrestien, tome 1.

- Fernández Ramos, Severiano (1997) El derecho de acceso a los documentos administrativos. Madrid: Marcial Pons.

- Ferrada, Juan Carlos (2003) "La autonomía del Banco Central de Chile: reflexiones acerca de este modelo institucional de gestión de la política monetaria". Revista Chilena de Derecho, vol. $30 \mathrm{~N}^{\circ} 1$.

28 Citado por García de Enterría, Eduardo. (2007) Las Transformaciones de la Justicia Administrativa: de Excepción Singular a la Plenitud Jurisdiccional. ¿Un Cambio de Paradigma? Madrid: Thomson, Civitas, 148 pp., p. 63. 
- Ferrada, Juan Carlos (2007) "Las potestades y privilegios de la Administración Pública en el régimen administrativo chileno". Revista de Derecho, Universidad Austral de Chile, vol. XX, $\mathrm{N}^{\circ} 2$.

- García de Enterría, Eduardo y Fernández, Tomás-Ramón (2000) Curso de Derecho Administrativo. $10^{\text {a }}$ edición. Madrid: Civitas, tomo I.

- García de Enterría, Eduardo (2007) Las Transformaciones de la Justicia Administrativa: de Excepción Singular a la Plenitud Jurisdiccional. ¿Un Cambio de Paradigma? Madrid: Thomson, Civitas.

- Muñoz Machado, Santiago (2006) Tratado de Derecho Administrativo y Derecho Público General. $2^{\text {a }}$ edición. Madrid: Iustel, Tomo I.

- Parejo Alfonso, Luciano et al. (1998) Manual de Derecho Administrativo. Barcelona: Ariel, vol. I.

- Rivero, Jean y Waline, Jean (2006) Droit administratif. $21^{\mathrm{a}}$ edition. París: Dalloz.

- SÁnchez Morón, Miguel (2007) Derecho Administrativo. Madrid: Tecnos, 2007.

- Schwartz. Bernard (1991) Administrative Law. $3^{\text {a }}$ edition. Bolton Toronto, London: Editorial Advisory Board Little, Brown and Company. 